\title{
Animated stunting counseling for department of Health Pagar Alam City based on multimedia
}

\author{
Buhori Muslim*, Ahmad N. Firdaus \\ Program Studi Teknik Informatika \\ Sekolah Tinggi Teknologi Pagar Alam \\ Email Korespondensi : *buhoristtp@gmail.com
}

\begin{abstract}
Stunting counseling carried out by the Pagar Alam City Health Office is still conventional, explaining directly by extension agents and power points so that people who take part in extension activities are easily bored, this study aims to design and build media for stunting prevention using animation at the Pagar Alam City Health Service based on multimedia using adobe. Flash Cs6 is able to attract interest and eliminate the feeling of boredom of extension participants, the development stage of this research uses the ADDIE method, the ADDIE model development design consists of five steps, namely analysis, design, development, implementation, evaluation. This animation was built and designed using adobe flash CS6 actionscript 2.0 to measure the validity level of the animation. This countermeasure is used, namely expert reviews of experts, or alpha tests obtained from the results to see the level of understanding and public interest before and after the use of stunting control animation. This animation is expected to be able to help the health office of Pagar Alam City in making stunting education more efficient. The final result of this research is an animation of stunting control to increase public knowledge and become an animated video for the assistant of Pagar Alam City Health Office.

Keyword: Counseling, Stunting, ADDIE, Animation, Video.
\end{abstract}

\section{Pendahuluan}

Teknologi informasi saat ini bukan suatu hal yang asing, aplikasi teknologi informasi semakin penting peran dan manfaatnya bila diaplikasikan dalam pekerjaan sehari-hari hal ini terlihat dari penggunaan yang merambah segala bidang [13]. Seperti terlihat pada bidang-bidang: kesehatan, pendidikan, perdagangan, telekomunikasi dan bidang jasa-jasa yang lainnya. Kecanggihan dan kemajuan teknologi informasi dapat diaplikasikan untuk mendukung menyampaikan informasi pada bidang kesehatan oleh karena itu perlu adanya inovasi baru untuk membuat animasi pada bidang kesehatan [8][15].

Pada observasi yang dilakukan pada Dinas Kesehatan Kota Pagar Alam Teknologi Informasi sangat diperlukan untuk aplikasi bidang kesehatan [5], untuk sarana pendukung kesehatan, sarana penyuluhan bidang kesehatan dan sebagainya [7]. Banyaknya aplikasi yang diperlukan dinas kesehatan ini maka pada penelitian ini di pilih satu bidang yaitu penyuluhan di Dinas Kesehatan Kota Pagar Alam, di pilih pembuatan sarana pendukung penyuluhan untuk stunting, menggunakan animasi dan didukung multimedia agar makin menarik dan tidak membuat bosan atau jenuh peserta pelatihan [1], di pilih penyuluhan stunting karena saat ini stunting merupakan hal yang menjadi topik pembahasan utama pada Dinas Kesehatan Kota Pagar Alam, dimana Dinas Kesehatan telah melakukan berbagai upaya tentang tata cara menanggulangi masalah stunting seperti melakukan kegiatan sosialisasi ke masyarakat. Selama ini sosialisasi yang dilakukan Dinas Kesehatan menggunakan teks, menggunakan aplikasi power poin [3]. 
Pada sosialisasi ini diikuti tokoh masyarakat, pihak kelurahan, kecamatan, UPTD Puskesman, Dinas Kesehatan maupun Dinas terkait lainnya juga perwakilan masyarakat usia produktif.

Animasi tentang stunting ini dibangun dengan adobe flash cs6 bertujuan meningkatkan daya tarik masyarakat untuk mengikuti kegiatan penyuluhan penanggulangan stunting [2][9]. Menggunakan animasi seperti ini maka kegiatan sosialisasi atau penyuluhan lebih berwarna dan tak membuat masyarakat yang mengikuti kegiatan sosialisasi mudah jenuh [4], pendekatan seperti ini materi sosialisasi diharapkan lebih tersampaikan kepada masyarakat. Animasi yang disampaikan berupa gabungan antara animasi, video dan teks [6][10]. Media penyampaian pesan yang berupa cara untuk menghindari atau mencegah terjadinya stunting pada balita [18]. Maka dari itu, penulis melakukan upaya pembaharuan media-media alternative komunikasi visual dalam bentuk animasi [16], media utama yang digunakan sebagai animasi dari iklan layanan masyarakat ini adalah dalam bentuk video animasi yang menarik [17][19], komunikatif dan efektif untuk meningkatkan kesadaran masyarakat terhadap bahaya stunting [7].

\section{Metode}

Metode penelitian yang dalam arti luasnya merupakan tata cara dilaksanakannya penelitian ini, mengikuti metode tertentu mulai analisis awal perumusan, pengumpulan data, analisis kebutuhan data, desain atau rancangan penelitian, sampai dengan hasil dan analisis data berkenaan dengan fokus masalah tertentu yang diselesaikan pada penelitian [14].

\subsection{Teknik Pengumpulan Data}

Pada penelitian ini dalam rangka pengumpulan data yang diperlukan pada penulisan, penulis menggunakan beberapa metode pengumpulan data, yaitu:

a. Observasi.

Pada kegiatan observasi ini peneliti turun secara langsung ke lapangan di Kecamatan Pagar Alam Selatan Kota Pagar Alam untuk melihat langsung anak balita dibawah lima tahun sebagai penderita penyakit stunting dan mengumpulkan data pendukung lainnya.

b. Wawancara.

Menurut Moleong (2011), wawancara merupakan percakapan dan Tanya jawab yang diarahkan untuk mencapai tujuan tertentu [11]. Pada penelitian ini peneliti melakukan wawancara dengan pihak yang melakukan kegiatan sosialisasi penanggulangan dan melakukan kegiatan tanya jawab langsung.

c. Kuisioner.

Menurut (Sugiyono, 2011) dalam Ferry, 2018 [3]. Penelitian berjudul "Multimedia pembelajaran simulasi instalasi sistem operasi windows dan software pendukung pada mata kuliah praktikum sistem operasi Sekolah Tinggi Teknologi Pagaralam" kuisioner merupakan suatu teknik pengumpulan data dimana responden mengisi pertanyaan atau pernyataan kemudian setelah di isi dengan lengkap dikembalikan kepada pihak peneliti.

d. Studi Pustaka.

Studi pustaka merupakan kegiatan penulis melakukan pengumpulan data bersumber dari buku, jurnal sebagai bahan referensi yang bisa digunakan sebagai acuan yang bertujuan untuk mendapatkan panduan diperlukan [12].

\subsection{Sistem Yang Diusulkan}

Berdasarkan analisa sistem penanggulangan yang sedang berjalan di Dinas Kesehatan Kota Pagar Alam pada saat ini, masih sangat banyak kelemahan yang terjadi pada saat melakukan kegiatan penanggulangan, dengan adanya berbagai kelemahan tersebut maka perlu adanya inovasi baru dari pihak Dinas Kesehatan dalam melakukan kegiatan penyuluhan mengenai penanggulangan stunting tersebut. Untuk itu peneliti mengusulkan sistem berikut. 


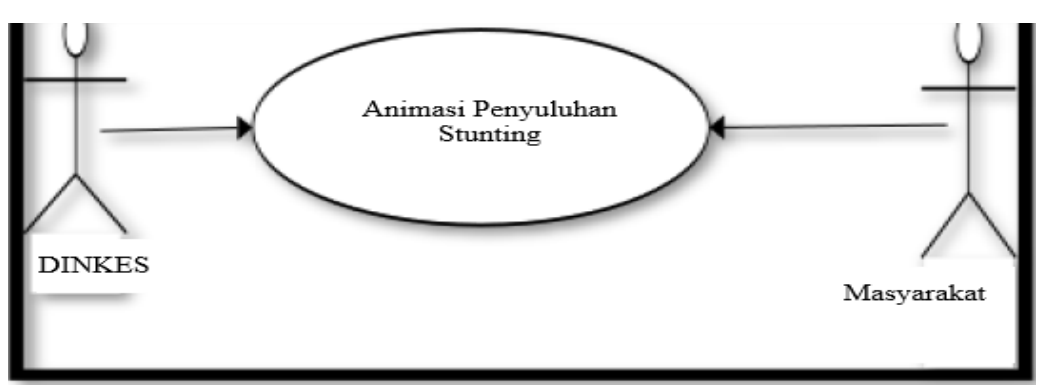

Gambar 1. Use Case Sistem yang Diusulkan

\section{Hasil dan Pembahasan}

Penelitian ini menghasilkan suatu sarana penyuluhan, berupa animasi penyuluhan penanggulangan stunting pada anak balita di Dinas Kesehatan Kota Pagar Alam berbasis multimedia. Penelitian dilakukan untuk membantu Dinas Kesehatan dalam penyediaan sarana sosialisasi atau penyuluhan agar lebih diminati, tidak membuat jenuh pada pelaksanaanya lebih efektif dan efisien sehingga peserta sosialisasi menjadi lebih paham pada materi sosialisasi yang disampaikan, karena selama ini Dinas Kesehatan melakukan sosialisasi masih menggunakan metode konvensional/ ceramah atau menyampaikan secara langsung. Untuk itu peneliti membuat video berupa animasi tentang stunting pada anak diharapkan bisa membuat masyarakat Kota Pagar Alam saat mengikuti kegiatan penyuluhan tidak mudah jenuh. Pembuatan animasi ini dilakukan berdasakan model pengembangan ADDIE yang memiliki beberapa fase yaitu analisis kebutuhan (Needs Assess), Perancangan (Design), Pengembangan (Development/Implement), Evaluasi (Evaluation). Dalam proses testing yang terdapat pada proses pengembangan (Development) untuk mengukur kevalidan multimedia interaktif dilakukan uji alpha (uji ahli media, materi, desain dan bahasa).

\subsection{Tampilan Scene Intro.}

Halaman ini merupakan halaman pembuka pada animasi penyuluhan penanggulangan stunting pertama kali dibuka maka akan dihadapkan pada tampilan pertama yaitu tulisan yang berupa stunting yang bergerak dari samping ke tengah.

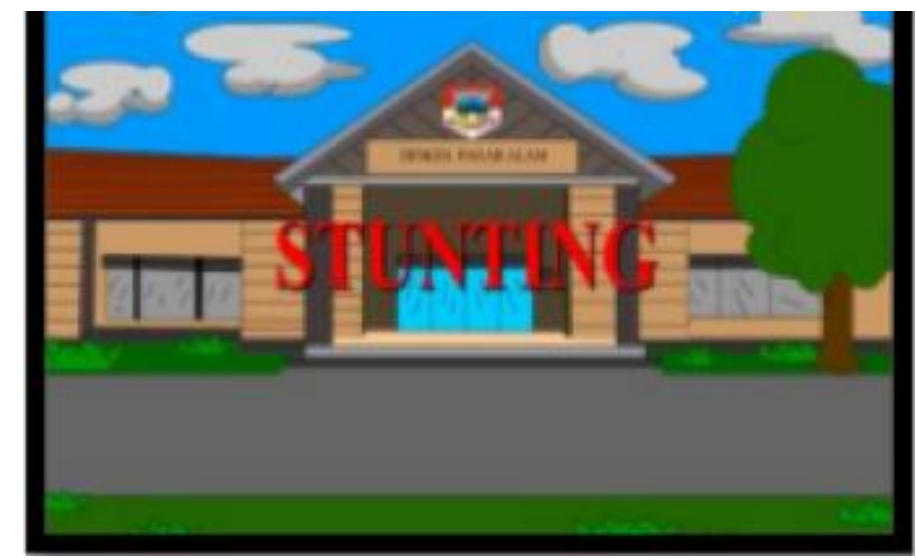

Gambar 2. Scane Intro.

Gambar 2. Mendeskripsikan bahwa tempat dan instansi yang mendukung dari pelaksanaan penelitian ini, yaitu Dinas Kesehatan Kota Pagar Alam. 


\subsection{Tampilan Scane tentang simulasi penyandang stunting}

Tampilan kedua yaitu menceritakan tentang tiga orang anak yang berdiri didepan kantor Posyandu yang mana pada anak yang berada ditengah mempunyai ukuran tinggi badan lebih pendek dari teman sebayanya, maka pertumbuhan anak ditengah tersebut mengalami gangguan dan ini dikatakan stunting.

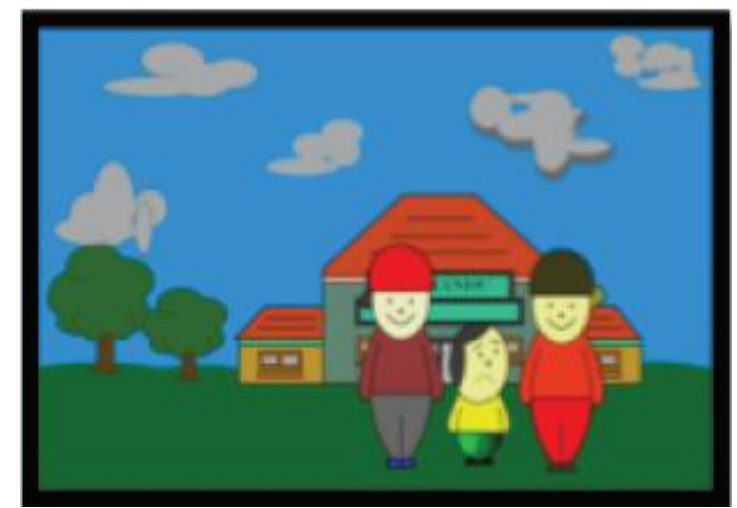

Gambar 3. Scane simulasi penyandang stunting.

Penjelasan Gambar 3. Sebagai deskripsi dari anak balita yang mengalami gangguan pertumbuhan akibat stunting jika dibandingkan fostur tubuhnya dengan kawan-kawan sebayanya.

\subsection{Tampilan scane penjelasan stunting}

Pada scane ini menjelaskan tentang apa itu stunting, dilengkapi audio, animasi dan penjelasan teks, sehingga diyakini peserta pelatihan bakal benar-benar memahami materi pelatihan tentang bahaya stunting bagi balita.

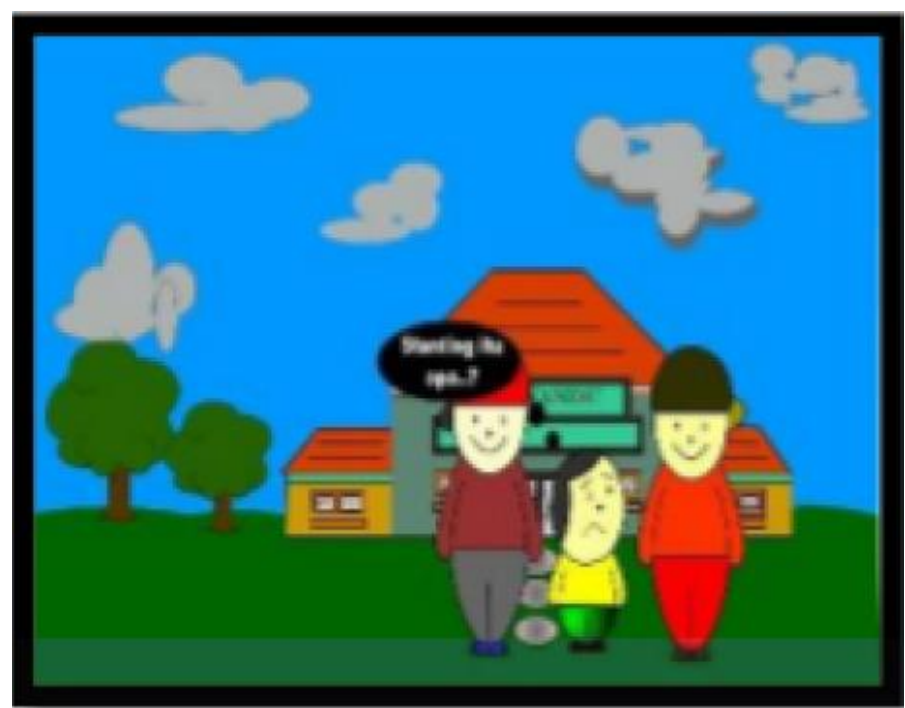

Gambar 4. Tampilan scane penjelasan stunting.

Maka dengan penjelasan melalui aplikasi yang berbasis multimedia ini peserta pelatihan tidak bosan, jenuh tetapi malah bersemangat dan memahami lebih baik materi sosialisasi.

\subsection{Tampilan scane penyebab terjadinya stunting}

Tampilan menu ini menjelaskan tentang apa saja yang menjadi faktor penyebab dari terjadinya stunting pada balita. 


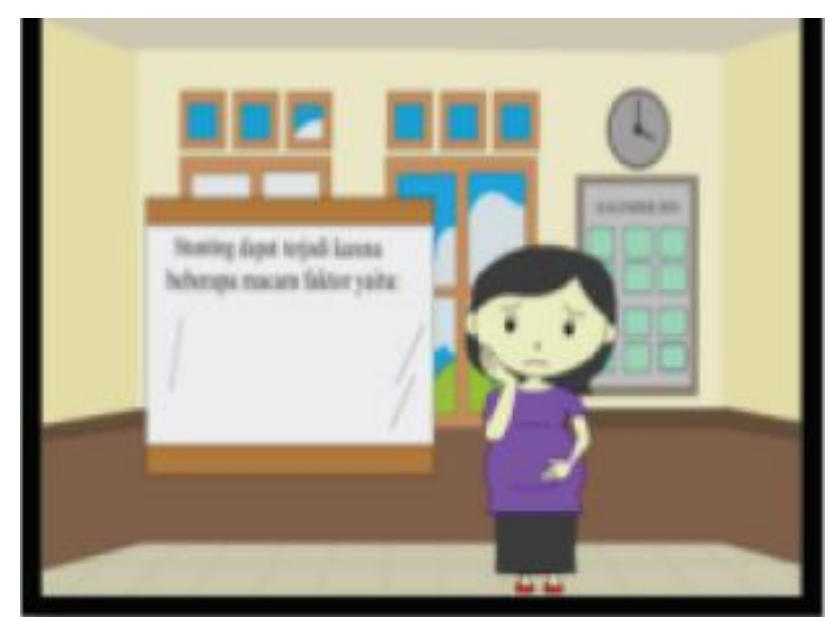

Gambar 5. Tampilan scane penyebab terjadinya stunting.

Melalui penjelasan Gambar 5. Peserta sosialisasi mampu memahami dengan baik, penyebab terjadinya stunting pada anak sehingga mampu menanggulangi bakal terjadinya stunting, sehingga anak tumbuh dengan stunting bisa dikurangi.

\subsection{Tampilan scane pencegahan stunting}

Tampilan menu ini menjelaskan bagaimana cara menghindari stunting yang mungkin terjadi pada balita saat nanti lahir.

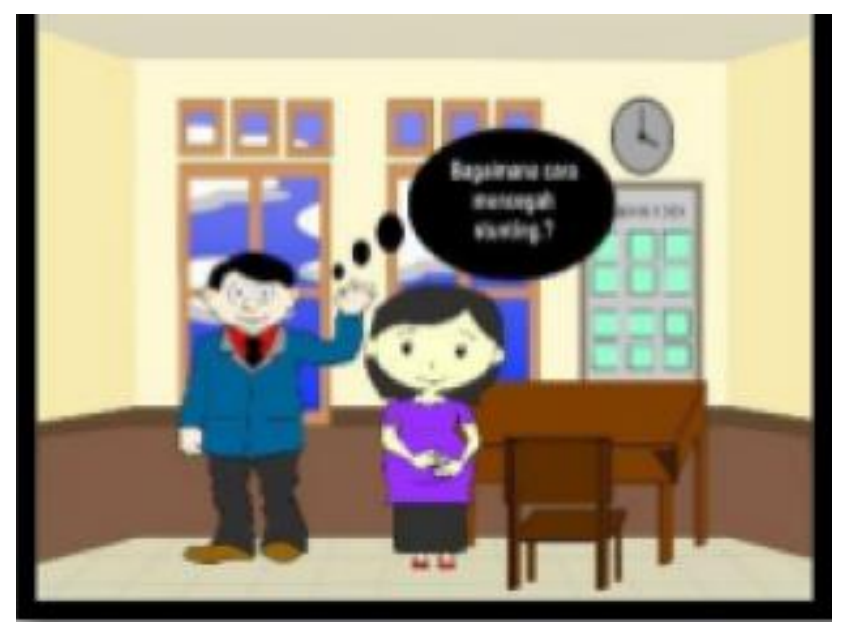

Gambar 6. Tampilan scane pencegahan stunting.

Seluruh peserta memahami dengan baik, cara-cara menanggulangi stunting setelah memahami faktorfaktor yang menyebabkan stunting dari penjelasan menu Gambar 5.

\section{Kesimpulan}

Berikut beberapa kesimpulan yang dihasilkan dari hasil penelitian yang sudah dilaksanakan:

1. Pada penelitian ini telah menghasilkan animasi penanggulangan stunting pada anak di Dinas Kesehatan Kota Pagar Alam berbasis multimedia yang berjalan pada PC/Laptop dengan sistem operasi windows 10 dan mampu diputar melalui handpon/HP.

2. Animasi penanggulangan stunting pada anak di Dinas Kesehatan Kota Pagar Alam berbasis multimedia telah berhasil dibangun menggunakan aplikasi adobe flash professional, adobe photoshop, adobe audition dan aplikasi filmora. 
Animasi penanggulangan stunting pada anak di Dinas Kesehatan Kota Pagar Alam berbasis multimedia dinyatakan valid. Data diperoleh dari komentar dan sarana pada lembar validasi uji alpha yang diberikan ahli bahasa, ahli materi, ahli desain dan ahli media. Animasi penanggulangan stunting pada anak di Dinas Kesehatan Kota Pagar Alam berbasis multimedia ini memiliki kriteria valid ditinjau dari aspek isi/materi, aspek penggunaan bahasa, aspek kelengkapan format bahan ajar, dan aspek rencana penyuluhan. Hasil validasi ahli bahasa menunjukan bahwa animasi penanggulangan stunting ini mempunyai validasi ahli kriteria baik dengan bahasa rata-rata skor 3.8 sedangkan hasil validasi ahli materi menunjukan bahwa animasi penyuluhan stunting ini sangat baik dengan rata-rata skor 5 dan hasil validasi ahli desain menunjukan bahwa animasi di penggulangan stunting ini sangat baik dengan rata-rata skor 4,3 kemudian nilai yang didapat dari ahli media rata-rata 4.75 dengan kriteria sangat valid.

\section{Ucapan Terimakasih}

1. Terima kasih kepada LPPM STT Pagar Alam

2. Panitia Senatik STT Adisucipto Yogyakarta

\section{Daftar Pustaka}

[1] Afrizal, A.S. (2015). Aplikasi pembelajaran matematika interaktif berbasis multimedia tingkat Sekolah Dasar kelas 1 (satu). Teknik informatika politeknik sekayu (TIPS), 10-21.

[2] Anwar, S. Schadaw, F.E dan Althafani. (2018). Perancangan animasi interaktif pengenalan Bahasa Sunda. Jurnal ilmu pengetahuan. 195-202.

[3] Ferry, P. (2018). Multimedia pembelajaran simulasi instalasi SO Windows dan Software pendukung pada mata kuliah praktikum SO Sekolah Tinggi Teknologi Pagar Alam. Betrik, 70-83.

[4] Firmantoro, K. Anton \& Nainggolan, ER. (2016). Animasi interaktif pengenalan hewan untuk pendidikan anak usia dini. Techno Nusa Mandiri, 103-110.

[5] Helmyati, S. (2019). Stunting permasalahan dan penanganan, Yogyakarta. Bulaksumur.

[6] Izwardi, D. (2019). Kebijakan dan strategi penanggulangan stunting di Indonesia. Gerakan masyarakat hidup sehat, 1-64.

[7] Kemenkes. (2017). 1000 Kabupaten/ Kota prioritas untuk intervensi anak kerdil (stunting). Jakarta: TNP2K-Unit Komunikasi.

[8] Jogiyanto HM, M. (2008). Sistem Tenologi Informasi. Yogyakarta: Andi Yogyakarta.

[9] Medcoms. (2017). Pasti bisa! Belajar sendiri Adobe flash pro cs6. Andi. Yogyakarta.

[10] M.Shalahuddin, R. A. (2018). Rekayasa Perangkat Lunak Terstruktur dan Berorientasi Objek. Bandung: Informatika Bandung.

[11] Maya. (2014). Adobe audition cs6. Andi. Semarang.

[12] Prabawati, T.A. (2013). Adobe Photoshop cs6. Andi. Semarang.

[13] Muslim, B. (2017). Pengantar Teknologi informasi Teknik Informatika. Yogyakarta: C.V BUDI UTAMA.

[14] Muslim, B. (2018). Quantitative Risk Analysis of Asset Information Technology at STT Pagaralam. Prosiding STTA Yogyakarta (Senatik 2018), STTA. Pages 501-509.

[15] Muslim, B. dkk. (2019). Proposal Of Infrastructure Information Technology Frame Work Togaf For Pagar Alam Town Governance. Jurnal Teknologi Informasi, Vol. 11, LPPM STIMIK Mura, pages 20-28.

[16] Pratiwi, B. \& Herlawati. (2015). Animasi interaktif pengenalan pembelajaran sistem peredaran darah pada SD Widya Bhakti Bekasi. Bina Insani ICT. 15-32.

[17] Purnasiwi, R.G \& Kurniawan, M.P (2013). Perancangan dan pembuatan animasi 2D "Kerusakan Lingkungan" Dengan Teknik Masking. Jurnal Ilmiah Dasi. 54-57.

[18] Sutarto, Mayasari D. \& Indriyani, R (2018). Stunting faktor resiko dan pencegahannya,

[19] Suyanto, M. (2015). Multimedia alat untuk meningkatkan keunggulan bersaing. Andi, Yogyakarta.

[20] Syahfitri, Y. (2011). Teknik Film Animasi Dalam Dunia Komputer, 1-5.

[21] Kendall, J.E. \& Kendall, K.E. 2010. Analisis dan Perancangan Sistem. Jakarta: Indeks. 